\title{
Innovation as a Determinant of Growth in Outperforming Emerging Markets: An Analysis of South Korea
}

\author{
Tina Maria Hintringer ${ }^{1}$, Vito Bobek ${ }^{1, *\left(\mathbb{D}, \text { Franko Milost }^{2} \text { and Tatjana Horvat }\right.}{ }^{2}$ \\ 1 Business in Emerging Markets Program, FH Joanneum University of Applied Sciences, 8025 Graz, Austria; \\ tina.hintringer@edu.fh-joanneum.at \\ 2 Faculty of Management, University of Primorska, 6000 Koper, Slovenia; franko.milost@fm-kp.si (F.M.); \\ tatjana.horvat@fm-kp.si (T.H.) \\ * Correspondence: vito.bobek@fh-joanneum.at; Tel.: +386-41-735-448
}

Citation: Hintringer, T.M.; Bobek, V.; Milost, F.; Horvat, T. Innovation as a Determinant of Growth in Outperforming Emerging Markets: An Analysis of South Korea. Sustainability 2021, 13, 10241. https://doi.org/10.3390/su131810241

Academic Editor: Marc A. Rosen

Received: 10 July 2021

Accepted: 11 September 2021

Published: 14 September 2021

Publisher's Note: MDPI stays neutral with regard to jurisdictional claims in published maps and institutional affiliations.

Copyright: (c) 2021 by the authors. Licensee MDPI, Basel, Switzerland. This article is an open access article distributed under the terms and conditions of the Creative Commons Attribution (CC BY) license (https:// creativecommons.org/licenses/by/ $4.0 /)$.

\begin{abstract}
Emerging economies and their speed of growth, competitiveness, and resilience are of great interest globally due to the high potential investors see in them. Innovation is one of the factors recognized to be the common ground of significantly outperforming economies. Therefore, identifying innovation benchmarks and how they impact economic success is relevant for a more straightforward evaluation of innovation in a country. This research focuses on the quantitative parts of innovation. Firstly, governmental interference, knowledge flows and networks, cultural and societal preconditions, and openness towards change are identified as notably relevant innovation enhancing factors in South Korea through case study analyses. Then, an analysis of the impact of quantitative innovation factors on the GDP in South Korea is conducted. The impact of quantifiable innovation factors, identified through literature review, on the GDP as the benchmark for economic growth is tested from 1995 until 2018 through a linear, multiple least squares regression to identify significant relationships between the chosen variables. Two out of five selected quantitative innovation factors have a statistically significant impact on the economic growth in the used model. The number of researchers per million people and the patent grants of residents is identified to be impactful innovation benchmarks.
\end{abstract}

Keywords: economic growth models; endogenous growth theories; exogenous growth theories; indicators on innovation; factors of innovation; innovation South Korea

\section{Introduction}

In the current socio-economic context, countries are facing serious challenges and are forced to find better and new methods to stay competitive and to increase their performance overall. Innovation has always been critical for long-term economic success. Throughout history, countries which have innovated successfully have typically been rewarded with growth, and access to new markets. Constant innovation has become a critical factor for achieving competitive advantages. Innovation has been widely acknowledged as a key mechanism for addressing sustainable development concerns. Many countries were accustomed to plans and actions that enforced their race toward competitiveness and ignored crucial environmental issues. Thus, in the last few decades there has been great interest among scientists, practitioners, and even the public, toward conserving the environment along with using resources efficiently (ecological concerns), improving the standard of human living (social challenges), and advancing long-term economic competitiveness (economic matters). Starting with the publication of the Brundtland Report in the United Nations, a productive discussion on the relationship between sustainability, transformation, and innovation began. This debate covers different levels of action and research, from environmental innovation and societal transitions or socio-technical transitions, to sustainability in multiple systems. 
Emerging markets contribute significantly to overall economic growth and are continuously gaining a share of the global economy. They show rapid growth, and their segment of middle-class and affluent consumers continues to expand. Another characteristic of emerging markets is that many low consumers, per World bank definition, remain, despite this expansion. Emerging markets are incredibly dynamic and fast-changing [1]. Therefore, economists are reasonably interested in influencing the resilience and growth of such emerging economies and their diversity regarding their culture, institutions, and organizations.

The McKinsey Global Institute mentions in its global report dealing with outperformers, published in 2018, that outperforming emerging markets experience a rise in their total factor productivity, which indicates an efficient use of a country's resources through innovation, management, and technology [2]. Especially Asian emerging markets are famous for their successful integration of innovation in their process of economic growth. For instance, South Korea is widely recognized for its innovation strategies [3].

According to McKinsey, an extension of the success of the outperforming emerging markets mentioned above could make it possible to add 11 trillion USD to the world economy by 2030 [2]. Due to the high impact of innovation as an endogenous economic growth factor observed in outperforming emerging markets, the factors contributing to innovation are of great interest globally. Therefore, this paper focuses on the composition of innovation and the factors that make emerging markets innovative and, consequently, lead to economic growth.

\section{Research Gap}

The innovation within a country comprises quantitative and qualitative factors and, therefore, is hard to measure. Papers and articles that focus on factors contributing to innovation as an endogenous growth-indicator that have been published so far concentrate either on quantitative factors at a macroeconomic level or, more often, on qualitative factors contributing to innovation at the level of particular organizations or industries in certain areas or countries [4]. However, the research results cannot be seen as the universal truth because of the unique development process of each economy.

This paper aims to identify qualitative factors for innovation that can contribute to economic growth in South Korea. Additionally, it seeks to identify representative quantitative factors of innovation contributing significantly to the GDP in South Korea. After these factors are identified, the authors aim to test whether these factors impacted its GDP in its development. Testing whether the numerical innovation factors identified can be statistically proven to have had an impact on the country's economic success will deliver a better understanding of the innovation factors that contributed to the economic success of South Korea as an outperforming emerging market.

The following assumptions have been designed:

A1: Public policies can be identified, contributing to innovational success in case studies dealing with South Korea.

A2: Knowledge flows and networks can be identified, contributing to innovational success in case studies dealing with South Korea.

A3: Societal and cultural environments can be identified, contributing to innovational success in case studies dealing with South Korea.

A4: The openness of a country towards change and new ideas can be identified, contributing to innovational success in case studies dealing with South Korea.

The following hypotheses have been designed:

Hypotheses 1 (H1). The innovation factor "investment in research and development" significantly impacts South Korea's GDP.

Hypotheses 2 (H2). The innovation factor "patent grants of residents" significantly impacts South Korea's GDP.

Hypotheses 3 (H3). The innovation factor "patent grants of non-residents" significantly impacts South Korea's GDP. 
Hypotheses 4 (H4). The innovation factor "tertiary school enrollment" significantly impacts South Korea's GDP.

Hypotheses 5 (H5). The innovation factor "number of researchers per million people" significantly impacts South Korea's GDP.

The statistical proof will reduce the empirical evidence gap concerning quantifiable innovation factors' actual impact on a macro-economic level. Furthermore, the paper aims to identify particularly influential innovation factors in Korea, partly transferred to other economies. The research model of this paper can test the impact of innovation factors in other economies and, therefore, functions as a template for measuring quantifiable innovation factors.

The numerical data needed was derived from the World Bank, where open data is available per country. Information regarding patents was provided by the World's Intellectual Property Organization (WIPO). Furthermore, consulting companies dealing with global development matters, such as McKinsey and Deloitte, acted as additional data sources. Further literature, case studies, and journal articles were searched via databases such as Science Direct, Research Gate, or Elsevier [5,6].

\section{Literature Review}

\subsection{Underlying Theories and Approaches}

The following theories provided the underlying framework for growth indicators and how innovation was derived as a subject to be analyzed further. Please note that not all traditional and new growth models can be described in this paper. The following theories provide the insights necessary for forming the methodology of this paper [7].

\subsubsection{Neo-Classical Growth Model}

Various growth theories and models have been developed in an attempt to grasp the complexity of the interaction between growth indicators in emerging markets. Excerpts of these theories are described briefly in this paper for a better understanding of exogenous and endogenous indicators of growth. Traditional growth theories focus on exogenous factors, whereas the neo-classical Solow-Swan model focuses on capital accumulation and labor or population growth. The Harrod-Domar model focuses on the level of savings and countries' capital-output ratio as primary factors [8]. The Solow-Swan model extends the Harrod-Domar model and describes economic growth as a dynamic input and output process, whereas the input factors are capital, labor, and technology [9]. If the input factors change, the output is affected. Capital is assumed to be subject to diminishing returns in closed economies in this model. Solow treats the technological process as an exogenous factor and assumes capital to be homogenous-only two examples of this model's limitations. Solow's model aids understanding, but most of its assumptions are not applicable in today's economy [10].

\subsubsection{Endogenous Growth Theories}

More recent theories, such as those developed by Paul Romer and Robert Lucas, consider endogenous growth and the factors contributing to it as significant forces behind economic growth. Those new theories put a greater emphasis on the concept of human capital and innovative ideas. Therefore, they are more relevant for this paper than the exogenous growth theories by Solow and Domar, even if they are helpful for general understanding [11]. Endogenous growth models state that human capital, knowledge, and innovation contribute significantly to economic growth. For instance, Romer and Lucas assumed that investment in human capital would spill over in the economy and would have the power to reduce diminishing returns. The technological process is no longer considered an exogenous growth factor but rather the result of innovative ideas resulting from investment in human capital. Furthermore, endogenous growth theories such as Romer's include many macro-economic assumptions that make gaining empirical evidence 
to support the theory complicated [12]. This paper focuses on identifying factors contributing to "innovation," which is assumed to be a significant indicator of economic growth in emerging markets in endogenous growth theories. Innovation has been selected as the focus due to its high relevance in outperforming emerging markets based on this theory.

\subsubsection{Eclectic Approach}

The McKinsey Global Institute (MGI) follows an eclectic approach and identifies outperforming emerging markets and their growth characteristics, which is relevant for identifying potential further factors contributing to innovation in this paper. Therefore, McKinsey's findings and selected indicators and factors are used as a basis for the selection of innovation factors in addition to other scientific articles dealing with this topic [2]. According to the results of the MGI, the two significant factors of growth observed in outperforming emerging markets are a pro-growth policy and large companies that are highly competitive in a country [2].

\subsubsection{Eclectic Approach vs. Traditional Growth Theories}

As mentioned above, traditional as well as endogenous growth theories are based on certain assumptions. The Solow-Swan model, for instance, includes assumptions such as a closed economy without trade, perfect competition, homogenous households, or no government [13]. These assumptions aim, rightly, to simplify the complexity of the world in order to make sense of it theoretically. However, simplicity does not only mean understandability but also a drift away from reality and applicability. For a reliable discovery of a country's growth-driving indicators, macro-economic theories based on many assumptions help general understanding but are insufficient for practical implications in today's complex world. The eclectic approach applied by the MGI mentioned above is not based on assumptions or mathematical theories but primarily on the analysis and comparison of the actual situation in emerging markets. The eclectic approach enables a higher degree of freedom concerning observations and a more open mind when identifying outstanding characteristics [2]. While theories work within a specific, predefined frame, the eclectic approach allows us draw conclusions about the world as it is, even though they might not always be expressed in a mathematical sense. The MGI looks at countries' qualitative and quantitative characteristics through their approach, which is crucial when analyzing innovation as a pro-growth factor of an emerging economy. It helps to get a holistic idea of innovation benchmarks and practically applicable improvement possibilities.

\subsection{Qualitative and Quantitative Factors for Innovation}

For a holistic identification of factors contributing to innovation, a separation of quantitative and qualitative factors is necessary. The collection of factors originates from extensive literature research of different papers dealing with innovation and the factors contributing to innovation.

The endogenous growth theory by Paul Romer focuses for a large part on innovative ideas as a tool to enhance economic opportunities and views unstable economic policies as a constraint to innovation and thus economic development [14]. Therefore, one can assume that stable public policies, including the regulation and tax system, government support, or macroeconomic policies, contribute to economic growth. Other qualitative factors include the knowledge flows and networks in a country, the societal and natural environment, the markets, and the customers within a market, as the manual by the organization for economic cooperation and development, published in 2018, suggests [15]. Furthermore, a country's openness towards change and new ideas is an essential factor influencing innovation within an emerging market, according to the paper "Innovation indicators throughout the innovation process," an extensive literature review about innovation indicators by Dallas and Blind [16]. The qualitative innovation factors of South Korea can be best identified through an extensive case study analysis on an institutional level. However, 
this paper focuses on quantifiable innovation factors and their impact on the country's GDP in the past 23 years.

The most popular quantitative, measurable factors that could be identified through extensive literature research to measure innovation in a country are issued patents and efforts in research and development processes [17]. The issued patents in a country can be considered the output of investment in innovative ideas that aim to contribute to economic success and growth. Other literature deals almost exclusively with research and development $(R \& D)$ as an indicator of enterprises' innovation. A study conducted by Deloitte found that R\&D investments work best for innovation combined with sufficient management and public policies, transferable on a macroeconomic level [18]. The latter underpins the importance of looking at qualitative and quantitative factors contributing to innovation to draw a holistic picture of a country's innovation factors. Based on the research summarized in this chapter, it is necessary to look at the innovation factors "issued patents" and "R\&D expenditures" of Korea and test whether these quantitative indicators can be statistically proven to directly impact the country's GDP.

Looking at the OECD innovation strategy, it becomes evident that innovation is started by human ideas resulting from specific qualifications, which Romer and Lucas state in their endogenous growth theory mentioned above. Diverse graduates from tertiary education, especially in science, technology, engineering, mathematics, business, social sciences, and education, are proven to lead to innovations that benefit a country's economy [19]. The World Bank defines tertiary education as: "Tertiary education is all post-secondary education, including public and private universities, colleges, technical training institutes, and vocational schools." Higher education is expected to result in a highly skilled workforce, which leads to economic advances through innovation [20]. Korea has had a knowledgebased economy since the mid-1990s, meaning that it depends on knowledge, a skilled labor force, and information, in aiming to achieve technical and scientific innovations [21]. For these reasons, tertiary education enrollment in Korea is selected as one of the quantifiable factors contributing to innovation. The aim is to test whether a significant direct impact from tertiary education enrollment in Korea on the country's GDP development can be identified.

Besides monetary R\&D expenditures and patent grants as the most popular expected output from this investment, it is essential to investigate the impact of the number of researchers in a country and their contribution to the GDP. The analysis of both factors is needed because a higher number of researchers does not naturally result in an equally higher number of patent grants, as the output of researchers is not always quantifiable as such but involves improvement strategies for institutions, policies, or other systems, too [22]. The number of researchers in a country and their impact on the GDP during the past 23 years is a quantitative innovation factor that stands for a specific numerical output and represents qualitative innovations, such as changes in public policies and improvements of knowledge-flows and networks.

Based on the literature review and as argued above, the following innovation factors have been selected, as shown in Table 1 .

Table 1. Overview of selected innovation factors.

\begin{tabular}{ll}
\hline Quantitative Factors of Innovation & Qualitative Factors of Innovation \\
\hline investment in research and development & public policies \\
issued patents of residents and non-residents & knowledge flows and networks \\
tertiary school enrollment & $\begin{array}{l}\text { the societal and natural environment } \\
\text { customers within a market } \\
\text { the openness of a country towards change and new ideas }\end{array}$ \\
\hline
\end{tabular}




\section{Methods and Research Design}

\subsection{The Research Method}

In the literature research above, public policies, knowledge flows and networks, societal and cultural environment, the type of customers within a market, and the openness of a country towards change and new ideas were identified as crucial qualitative innovation factors in outperforming emerging markets. For this part of the thesis, case studies dealing with innovation in South Korea were selected to confirm or refute the assumptions defined.

As a scientific method, case studies are an excellent tool for making complex theories understandable and discovering new information [23]. Multiple cases were chosen to attain representative results and make theoretical assumptions more feasible. About 3-10 case studies are seen as a good case-study analysis benchmark, including multiple studies [24].

Case studies dealing with implementing innovation activities on a national level were chosen to analyze South Korea's national innovation system (NIS) development process to extract the relevant contributing factors. Furthermore, a case study focusing on innovation activities in small and medium-sized enterprises (SMEs) was selected to analyze if and how national firms benefit from the South Korean innovation system. The general factors contributing to innovation in a functioning system should not differ much from a national to an organizational level, so it was essential to analyze both perspectives to detect parallels or particularities.

In order to gain a better understanding of innovation in South Korea, the selected case studies were summarized, and questions to be answered through the analysis were identified. The problems the case deals with were described in next, and the case-specific processes and measures taken were explained. The Results section lists the effects the implemented processes had on the case-specific problems, and the factors contributing to innovation could be extracted from the analysis at this point.

The research method used for testing the impact of the selected innovation factors on South Korea's GDP is multiple regression. The accuracy of a multiple regression vanishes when too many independent variables are tested at once. So not every factor connected to innovation that might be positively correlated to the GDP can be included in the model. For this reason, only the most apparent quantitative factors discovered through the literature review have been used for the multiple regression. This is also the main reason why multiple regression has been chosen as a quantitative method in this paper.

Multiple regression has the purpose of identifying the relationship between various independent variables and one dependent variable. In this case, the independent variables are the investment in research and development, the issued patents of residents and non-residents, the school enrollment tertiary gross, and the number of researchers per million people in Korea. The dependent variable is the GDP [25]. Since the GDP can be correlating with and explained through numerous different variables, the regression must be performed with enough data points over a sufficient number of years to gain solid reliability. In this paper, the data used for the multiple regression was retrieved from the World Bank [20]. Data from 1995 until 2018 have been analyzed.

In this paper, a linear multiple regression model is being used, of which the model specification states that $\mathrm{Yi}$, the dependent variable, is modeled as the function of the independent variables with corresponding coefficients, together with the constant term (BO) and an error term (e) [26]. Before running the model, an exploratory data analysis was conducted to know the data's features and check if it is suitable for the model. The regression model fits a linear equation to the data observed where the dependent variable $y$ is associated with every value of the independent variable $x$ [27]. The ordinary least-squares model, the line virtually fitted in between the data points, is detected mathematically.

The ordinary least squares model calculates the best fit for the line by minimizing the sum of the squares of the vertical difference from each of the data points to the line. Thus, the regression model line is virtually drawn where the data points are the closest to the line, and the variance is minimized [28]. After running the linear, multiple least squares regression with the selected independent and dependent variables, a summary of 
the model can be printed, the results can be viewed, and the data can be analyzed. The multiple regression is being run in $\mathrm{R}$, a free software program for statistical computing.

To avoid an autocorrelation bias, which often occurs in time series data, the DurbanWatson test was run for the regression model to avoid misinterpretation due to the residuals' positive autocorrelation overestimating the statistical significance of the results [28].

\subsection{The Equation}

In the literature review above, the innovation factors to be analyzed through multiple regression have been identified, as shown in Figure 1. According to these findings, quantitative innovation is composed out of the investment in research and development (RD), the issued patents of residents and non-residents (PR, PNR), the school enrollment tertiary gross (EDUC), and the number of researchers per million people (NR). As innovation is expected to contribute to Korea's economic growth, the influence of the quantitative innovation factors on the GDP is analyzed through multiple linear regression to reject the 0 hypotheses, if possible. Based on the findings, the following function can be assumed:

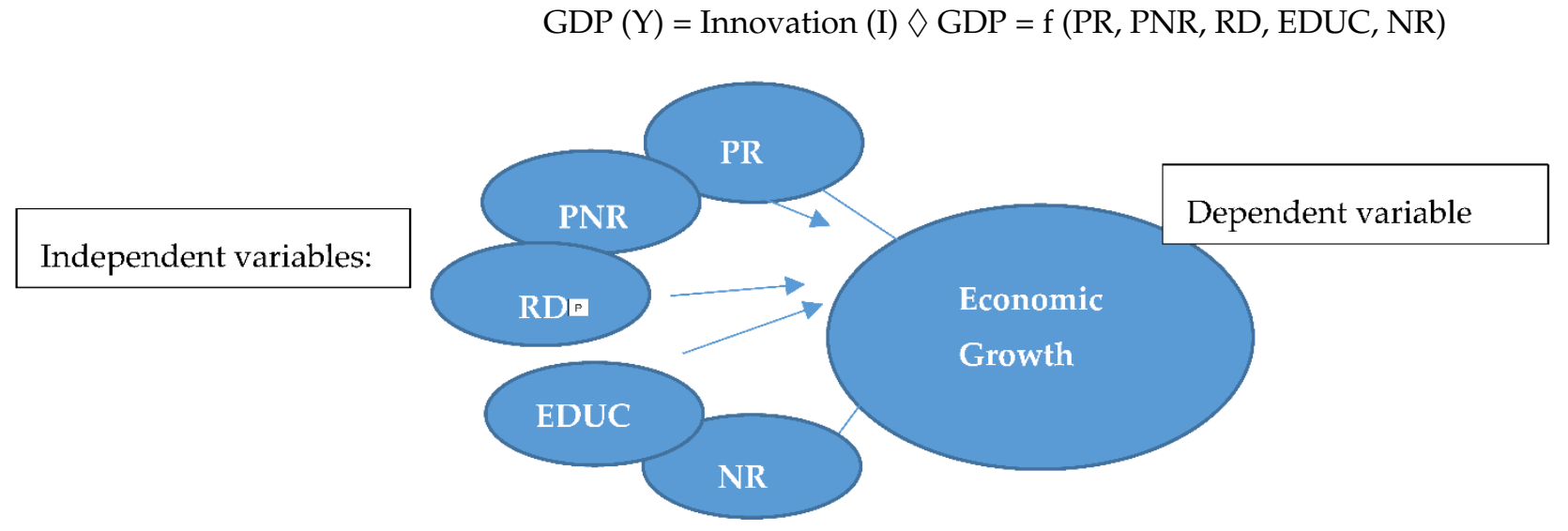

Figure 1. The research framework. Source: own illustration.

Thus, the equation for the multiple linear regression comes to the following form:

$$
Y G D P=\$ 0+\beta 1 P R+\beta 2 P N R+B 3 R D+B 4 E D U C+B 5 N R+e
$$

The constant in the model is $B 0$, also called intercept, which is the expected mean value of the dependent variable " $y$ ", when all independent variables " $x$ " equal 0 [29]. " $e$ " is the notation for error terms and represents the residuals, which refer to the sum of deviations within the regression line. The error terms explain the variation between the theoretical fitted value of the model and the unfitted, observed results [30].

\section{Case Study Analyses}

Case one was selected as a valuable contribution to this paper because it dealt with the general development of innovation activities in South Korea and portrayed if and how innovation policies contribute and contributed to economic success, how they changed over time, and how they were implemented. The case published by the Taiwan Research Institute described the implementation of policies to foster national development strategies through innovation in Asia. The landscape of policies encouraging innovation in science and technology in China, South Korea, and Taiwan was described and compared [31]. In this analysis, the focus lay solely on South Korea. The implemented methods led to the fast development of an internationally competitive growth strategy for South Korea. Through this strategy and Korea's strong focus on technological innovations, it managed to become well established in high-tech industries, such as telecommunication, automobiles, or semiconductors [31]. 
The analysis of the selected case study made it possible to identify the following factors that contributed to the implementation of Korea's successful innovation system during its development:

- Networks of national industrial conglomerates

- Networks of knowledge

- Independency of foreign-owned firms to a great extent

- Interference of government

- Highly centralized decision-making processes

- High acceptance of government interference

- Establishment of innovation-fostering institutions

- Openness towards collaboration with foreign scientists and engineers [31].

Case two was selected for this thesis because it implemented innovation measures on the South Korean business environment, differing between chaebol and SMEs. These developments were considered relevant for this paper's research objective as the implemented measures revealed what factors fostered the development of Korea's national innovation system. The role of research institutes was crucial for developing an innovation system, but the efficiency of these institutes can impact South Korea's future innovation activities. This case dealt with the issues regarding efficient technology transfer and the governmental reactions to those challenges. The case study analyzed the factors contributing to Korea's competitiveness and its challenges during and after the economic crises.

Furthermore, the case by Gang and Abetti provided a discussion about policies and activities that could be implemented by the Korean government, concerning their funded governmental research institutes (GRIs), in order to provide a functioning innovation system that would not only benefit chaebol. However, it could also foster innovation in SMEs [32]. The analysis of the selected case study makes it possible to identify the following factors that contributed to the implementation of Korea's successful innovation system [32]:

- Evaluation of the efficiency of established institutions

- Implementation of law and policies to foster innovation and distribution of resources

- Incentives for the establishment of networks including public and private institutions

- Support of SMEs regarding funding and establishment of R\&D activities

- Reduction of the predominance of chaebol

- Readiness of the market for innovation and technology

Case three was chosen because it dealt with innovation activities that enhanced the performance of IT organizations in South Korea from the perspective of SMEs. While cases one and two analyzed innovation-contribution factors from a macro-economic perspective, case three analyzed innovation-enabling activities from the standpoint of Korean firms, on the example of the IT industry. This perspective was of high relevance for this paper, as the innovation possibilities of organizations reflected the effectiveness of governmental interference through the establishment of institutions, laws, programs, and regulations. Qualitative innovation activities can only be determined when considering how both initiatives performed on a national level, and the way the enterprises located in the country and their performance was influenced by these activities. The analysis of the interplay of both perspectives was highly relevant for delivering a holistic picture of Korea's most crucial qualitative innovation factors. The case study focused on the possibilities for innovation activities for South Korean SMEs and to which degree they are executed in small Korean companies compared to the country's large conglomerates. The chosen study dealt with the value of innovation networks for Korean SMEs. The paper by Lee et al. analyzed the ways Korean firms use available information, their collaboration patterns with other firms or universities, and how these patterns correlate with innovational success. Furthermore, it presented collaboration cases of SMEs and suggested functioning innovation models, differing between an exploration strategy, meaning the development of innovations for new customers; and an exploitation strategy, meaning the improvement 
of existing technology for existing customers [33]. The analysis of the selected case study made it possible to identify the following factors that contribute to innovation activities in Korean SMEs [33]:

- research about and assessment of innovation activities in Korean SMEs

- intermediary associations to facilitate the construction of networks, limit risks, and maximize opportunities

- $\quad$ assessment of needs and deficiencies of the NIS

- the openness of SMEs towards external sources of information and knowledge

- networks of SMEs

- advantages/incentives for all network participants through increased collective competitiveness against larger firms.

\section{Results of Case Study Analyses}

In the analyzed cases, knowledge flows and networks were relevant for developing the national innovation system to exchange knowledge with external sources such as experts from abroad or other companies. Furthermore, networks built the base of the chaebol culture, which played a significant role in the beginnings of South Korea's innovation development. Thus, knowledge flows and networks are identified to have contributed to South Korea's innovational success through networks of knowledge, networks of SMEs, networks of national industrial conglomerates, and networks of suppliers or customers [31-33].

In the analyzed cases, openness was relevant for developing the national innovation system as the prerequisite for exchanging knowledge, establishing fruitful networks, and considering external sources of information, while collaborating with other firms or engineers from abroad. Thus, openness was identified to have contributed to the successful establishment of South Korea's innovation system through the openness from the government or leaders in SMEs towards collaboration, towards performance assessments in SMEs or the NIS as a whole, and towards external sources of knowledge customers [31-33].

In the analyzed cases, the societal and cultural environment was beneficial concerning the efficient decision-making processes and the high acceptance of government interference through the hierarchical, collectivistic, and long-term oriented culture embedded in Korean society. The market readiness for new technology was primarily determined by the stage of development the country had evolved to by the time the NIS was implemented. However, South Korea's cultural features were beneficial for establishing innovation networks, intermediary institutions, and the long-retained independence of foreign-owned firms. Thus, the societal and cultural environment in the respective market of South Korea was identified to have contributed to the successful establishment of the national innovational infrastructure customers [31-33].

In the analyzed cases, public policies were relevant in several contexts. Firstly, governmental interference led to a less dominant chaebol and a better allocation of resources through that. The establishment of innovation fostering institutions and intermediary organizations to enhance SMEs' innovation activities also happened due to the Korean government's interference. Secondly, assessing the efficiency of institutions dedicated to innovation and assessing smaller firms' innovation activities can be considered the basis of innovation processes and induced by the government. Thirdly, the choice of providing advantages and incentives for participating in networks or providing the possibility to own patents are necessary to increase the openness towards networking and conducting innovation activities. Thus, public policies in combination with governmental interference are identified as significant contributing factors for the formation of South Korea's national innovation system customers [31-33].

\section{Results of Quantitative Analysis}

After an exploratory data analysis, a multiple, linear, ordinary least squares regression was run in $\mathrm{R}$ to examine the relationship of selected independent variables, which are assumed to contribute to innovation in South Korea, with the dependent variable, the 
GDP. Scientific notations are being used in the table in column "Estimate" and column "St. Error" to make the high numbers used in this analysis appear more lucid. Data from the World Bank [20] from 1995 until 2019 has been analyzed. Table 2 shows the results of the regression.

Table 2. Regression results.

\begin{tabular}{lllll}
\hline Variable & B-Coefficient & St. Error & $t$ Value & $p$-Value \\
\hline Tertiary Education Enrollment Gross (EDUC) & $3.45 \times 10^{5}$ & $2.675 \times 10^{9}$ & -1.333 & 0.2012 \\
Number of Researchers/Million People & $3.735 \times 10^{8}$ & $1.370 \times 10^{8}$ & 2.727 & 0.0149 \\
(NR_RESEARCHERS) & $3.45 \times 10^{5}$ & $1.241 \times 10^{7}$ & -2.021 & 0.0603 \\
Patents Non-Residents (Patents_Non_Residents) & $1.145 \times 10^{7}$ & $4.429 \times 10^{6}$ & 2.585 & 0.0199 \\
Patents Residents (Patents_Residents) & $3.45 \times 10^{5}$ & $1.940 \times 10^{11}$ & -1.545 & 0.1420 \\
Research and Development Expenditures (RD) & $7.581 \times 10^{11}$ & $3.828 \times 10^{11}$ & 1.981 & 0.0651 \\
Constant/Intercept & 0.9800 & & & $p$-value 0.00000000000109 \\
Multiple R & & & & $p$-value $=0.06413$ \\
Adjusted R & & & & \\
F-value & 0.9726 & 131 & & \\
Result Durbin-Watson Test & 1.794 & & & \\
\hline
\end{tabular}

Source: Own calculation.

Table 2 shows that the adjusted R-squared is relatively close to 1 , which generally indicates that the chosen model fits the data and explains most of the variability around its mean [34]. As one can derive from the table above, the f-value is statistically significant with a $p$-value $<0.05$. Therefore, the chosen model, including the chosen independent variables, fits the data well compared to the intercept-only model, which does not include independent variables. It can be assumed that the independent variables added to the equation improve the model's fit as a consequence [35].

The multiple regression residuals were analyzed and plotted to assess the appropriateness of the chosen regression model. Most of the data points are distributed rather symmetrically, and there are no clear patterns visible, as one can derive from the residuals plot attached at the end of the paper. Besides this, the residuals move around the lower digits of the $y$-axis. Therefore, the assumption of a linear relationship between the independent and the dependent variables was respected. The QQ-plot supports that statement as most of the residuals move on the dashed line, indicating linearity. The horizontal line and the randomly spread data points in the scale location plot attached in Appendix A (Figures A1-A5) indicate that the assumption of homoscedasticity was respected. The residuals vs. leverage plot shows no outliers with high Cook's distance scores (outside the Cook's lines), which means that no outliers negatively influence the regression results [36].

The regression with the variable "research and development expenditures" (RD) results in a $p$-value of 0.142 . The $ß$-coefficient in the table shows that a simulated increase of the R\&D expenditures is estimated to decrease the GDP. The $p$-value $>0.05$ suggests that the examined relationship between R\&D expenditures and the dependent variable is not significant in this model. This result provides evidence against the hypothesis.

The regression with the granted patents of residents (Patents_Residents) results in a $p$-value of 0.0199 , indicating the statistical significance of the relationship between the independent and the dependent variable. Therefore, it poses strong evidence for the hypothesis. As the table above shows, an increase in patents is estimated to increase the GDP in this model. A rise in the number of granted patents of non-residents (Patents_Non_Residents), on the other hand, is not estimated to contribute to a rise of the country's GDP in this model.

The $ß$-coefficient of the number of researchers per million people (NR_RESEARCHERS) indicates that a rise in number is estimated to result in a higher GDP. The $p$-value for the regression of this variable shows 0.0149 . Thus, the $p$-value is $<0.05$ and is, therefore, statistically significant. The result of the regression with this variable indicates strong evidence for the hypothesis. 
The independent variable gross tertiary education enrollment (EDUC) is not proven to positively influence the economic growth of South Korea in this model. Additionally, the $p$-value of 0.2012 is $>0.05$, and, therefore, this result is not statistically significant in this model. The regression result with this variable indicates strong evidence against the hypothesis.

The Durbin-Watson test (DW) result has been conducted to determine whether the regression residuals are autocorrelated 1.794. The ideal result of the DW is 2.0. Therefore, the result indicates little positive autocorrelation but is within the normal range of 1.5-2.5 for regression models. The $p$-value of 0.06413 is $>0.05$ and, thus, confirms that true autocorrelation cannot be deducted from the test result [37].

It is pertinent to note that the results of experimentally inflicted changes on the regression model indicate that the independent variables are not entirely independent from each other, which causes some of the $\beta$-coefficient estimates to be sensitive to changes in the model. Sensitivity is inevitable when measuring the chosen leading indicators of innovation, as some of them are, by nature, correlated amongst each other. Experiments with removing and adding the selected innovation factors in different orders from and to the regression model have shown that the multicollinearity in this calculation does not affect the variables that show statistical significance in Korea; $p$-values stayed stable through the tentatively inflicted changes on the model.

\section{Assumption- and Hypothesis-Related Outcomes}

In the initial part of this section, the first aim of the research "Which qualitative factors for innovation can be identified to contribute to economic growth through the in-depth analysis of selected case studies in South Korea?" is addressed with the evidence collected from the country-specific case study analysis focusing on innovation in South Korea.

\subsection{Public Policies}

In all three cases, public policies and rules or regulations introduced by the Korean government could be identified as contributing factors to the country's successful innovation system. The introduction of policies or regulations led to a decline in Korean chaebol's predominance, a better technology transfer between research institutions and industries, and an overall better distribution of resources. Furthermore, the Korean government created innovation-fostering institutions to perform R\&D and intermediary associations to encourage networking, enhancing the innovational output of SMEs. The exchange of knowledge and the pooling of abilities enabled more accessible funding for innovation in SMEs and, as a consequence, the rise of innovational output customers [31-33].

While introducing policies and establishing innovation-fostering institutions is of great importance, the case study analysis revealed the evaluation of the efficiency of established institutions and the assessment of innovation activities in organizations as crucial factors contributing to innovation in South Korea.

Therefore, the assumption that public policies can contribute to innovational success in South Korea can be confirmed but can be categorized as a subfactor of the high level of governmental interference in South Korea.

\subsection{Knowledge Flows and Networks}

Knowledge flows and networks were dominant innovation factors in all of the three analyzed cases. Inefficiencies of knowledge flows were identified to be fatal for South Korea's NIS. A lack of technology transfer from research institutions to industries destroys the balance of input and output of R\&D, leading to a low return on investment. Furthermore, network models have been shown to improve the competitiveness of SMEs through pooling resources and focusing on core competencies to overcome limitations in innovational productivity. The case study analysis shows that the entire South Korean economic success has primarily been built on networking. It is also how the chaebol became so powerful and 
the reason for the efficiency of their R\&D departments, which was often much higher than the efficiency of the publicly-owned research institutes' customers [31-33].

Furthermore, the acceptance of external knowledge was essential to foster innovational activities in South Korean SMEs because it is a prerequisite for further collaboration, as proposed in case three. Additionally, the Korean government sought technological expertise from abroad during the development process of the NIS and used the knowledge to evolve.

For these reasons, the assumption that knowledge flows and networks contribute to South Korea's innovational success can be confirmed through the conducted qualitative research.

\subsection{Societal and Cultural Environment}

Societal and cultural environments could be identified as influencing the success of government interference, the readiness to accept new technology, and the participation in innovation fostering networks in all three cases. South Korea was largely independent of foreign firms during the chaebol system, and its decision-making processes were highly centralized. This combination allowed the economy to develop its NIS largely independently from foreign investors and react to emerging opportunities promptly. Furthermore, South Korea's societal features and collectivistic culture contributed to the fast acceptance of technological change, new policies, and regulations. As the Republic of Korea already shows signs of entering the stage of mass consumption and is more than capable of maintaining solid economic growth, its readiness of the market for innovation and technology is, naturally, part of the country's economic development stage, which is favorable for innovation on a macro-economic level as well as on an industry-level [31-33].

Therefore, the assumption made that societal and natural environments contribute to the innovative success of South Korea can be confirmed based on the results of the conducted case study analysis.

\subsection{Openness towards Change and New Ideas}

In all three cases, the acceptance of external knowledge and the exchange of knowledge with external parties were significant contributing factors for developing the South Korean innovation system. While South Korea's cultural features can be considered to be the precondition for openness towards governmental interference and technological change, openness towards new ideas was revealed to be a prerequisite for fostering innovational activities in SMEs on the level of local organizations, and on a macro-economic level, regarding the establishment of institutions and the introduction of policies and regulations to combat inefficiencies of the NIS customers [31-33].

The collaboration with foreign scientists and engineers to improve the NIS and the openness of SMEs towards other SMEs with other specializations required openness to be successful and further improve the innovational output of South Korea. Furthermore, the country assessed its innovation activities in government-owned research institutes and in private companies to act on them. The assessment of possibilities and potential weaknesses requires openness towards change and the willingness to develop new ideas. Additionally, the identification of core competencies and deficiencies to maximize output through collaboration networks with other firms, as proposed in case three, requires the openness to act self-reflectively regarding new processes and innovative ideas [31-33].

For these reasons, the assumption made that openness towards change and new ideas contributes to innovational success in South Korea can be confirmed through the conducted analysis.

In this part of the section, the second aim of the research, "What quantitative factors, the representative for innovation, contribute significantly to the GDP as the benchmark of economic growth in the outperforming emerging market of South Korea?" is addressed with the statistical evidence acquired through linear, multiple least squares regression. 


\subsection{Investment in Research and Development}

In the model specified for South Korea, the significance of the influence of the investment in research and development on the GDP could not be proven. A $p$-value $>0.142$ presents evidence against the respective hypothesis, implying that the innovation factor "investment in research and development" significantly impacts South Korea's GDP.

\subsection{Patent Grants of Residents}

The regression analysis result shows that the hypothesis, implying that the innovation factor "patent grants of residents" significantly impacts South Korea's GDP, may be confirmed due to a $p$-value as little as 0.0199 . Therefore, enough evidence for the acceptance of the hypothesis is given. Thus, the innovation factor "patent grants of residents" significantly impacts South Korea's GDP according to this research model's results.

\subsection{Patent Grants of Non-Residents}

On the contrary, patent grants of non-residents do not significantly contribute to Korea's GDP, according to this regression model's results. The independent variable's impact on the dependent variable could not be proven to be statistically significant with a $p$-value $>0.05$. Therefore, it is not scientifically justified to confirm the hypothesis, implying that the innovation factor "patent grants of non-residents" does significantly impact South Korea's GDP.

\subsection{Tertiary Education Enrollment}

In this analysis, the variable tertiary education enrollment could not be proven to impact Korea's GDP on a significant level directly. There is no evidence for the confirmation of the hypothesis in this research model, implying that the selected innovation factor "tertiary school enrollment" does significantly impact South Korea's GDP. Thus, the variable tertiary school enrollment does not directly impact the dependent variable in this model.

\subsection{Number of Researchers}

The result of the regression analysis shows a $p$-value of 0.0149 in this variable. Therefore, the confirmation of the hypothesis that the innovation factor "number of researchers per million people" significantly impacts South Korea's GDP, is statistically justified. Thus, it can be said that the number of researchers per million people does significantly influence Korea's GDP.

\subsection{Summary}

Two out of five selected innovation factors, analyzed through the linear, multiple least squares regression from 1995 until 2018, exhibit a statistically significant relationship with South Korea's GDP. The results show that residents' number of patent grants and the number of researchers per million people significantly impact Korea's GDP. The tested innovation factors patent grants by non-residents, tertiary education enrollment, and $R \& D$ expenditures, on the other hand, could not be proven to benefit the GDP of the country directly.

Thus, the first question in the paper is that the quantitative innovation factors number of researchers per million people and the number of patent grants of residents contribute significantly to the GDP as the benchmark of economic growth in the outperforming emerging market of South Korea. Figures 2 and 3 show the relationships between the dependent variable's data points and the statistically significant independent variables. 


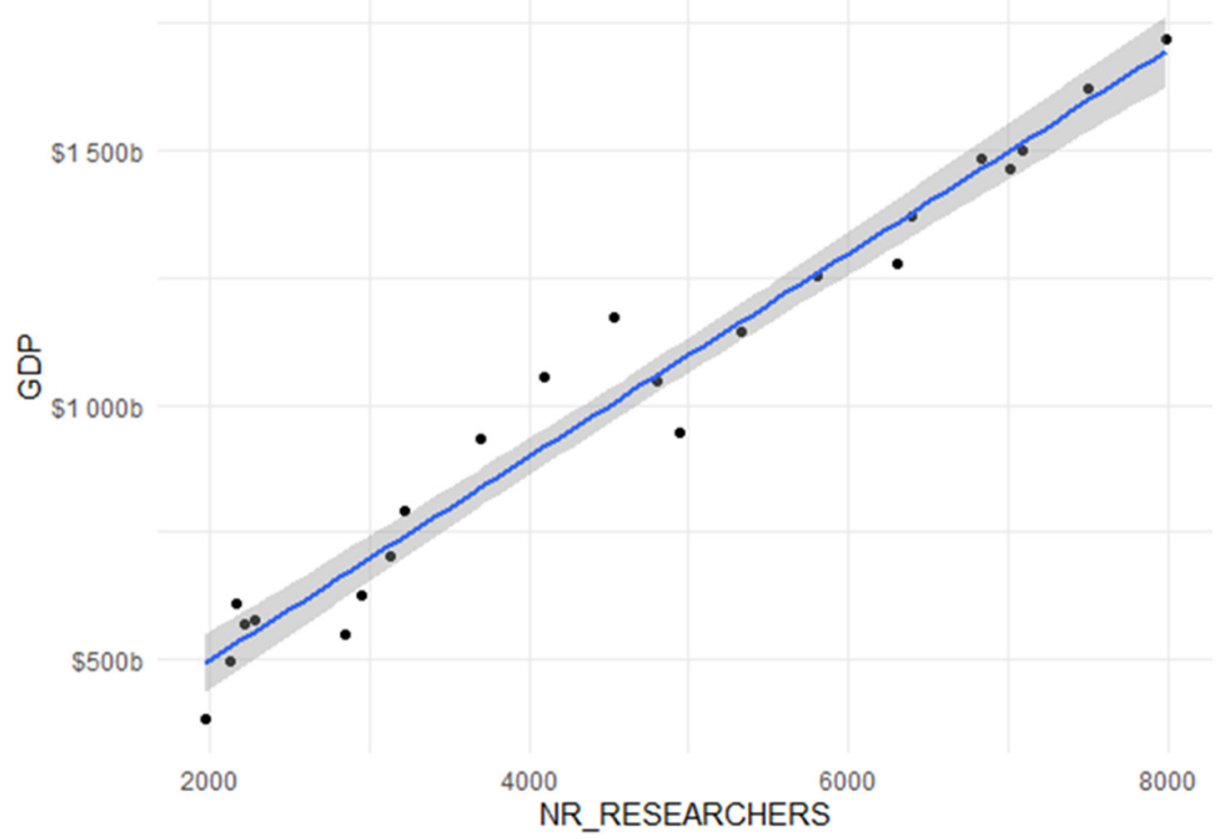

Figure 2. GDP in current USD and the number of researchers per million people in Korea 1995-2018. Source: Own calculation \& illustration.

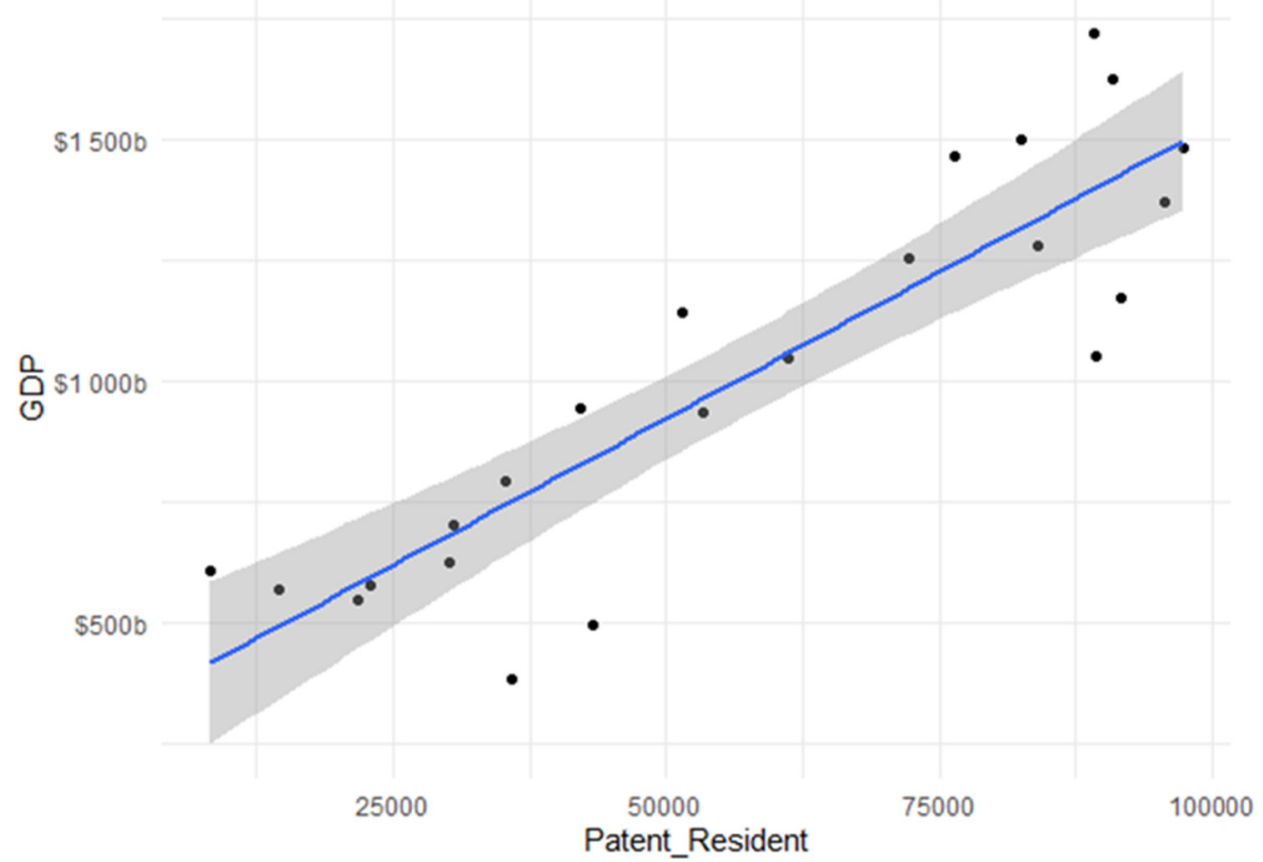

Figure 3. GDP in current USD and the number of patent granted to residents in Korea 1995-2018. Source: Own calculation \& illustration.

\section{Discussion}

\subsection{Qualitative Part}

The four factors, public policies, networks and knowledge flows, societal and cultural environments, and openness towards change and new ideas, were assumed to benefit the innovational success of the outperforming emerging market of South Korea. All four of the assumptions made could be confirmed through a case study analysis dealing with innovation on a macro-economic level and an organizational level in the respective market.

In addition to the confirmed qualitative innovation fostering factors, governmental interference was one of the main contributing factors for South Korea's successful innovation 
system. While public policies could be of high importance for developing the country's NIS, they can be seen as a subcategory of governmental interference.

Thus, governmental interference and the rules and regulations that result from this interference, networks and knowledge flows, societal and natural environments, and the openness towards change and new ideas were identified as highly relevant contributing factors in the case of South Korea's national innovation system.

Figure 4 shows an overview of the crucial, qualitative, innovation enhancing factors in South Korea.

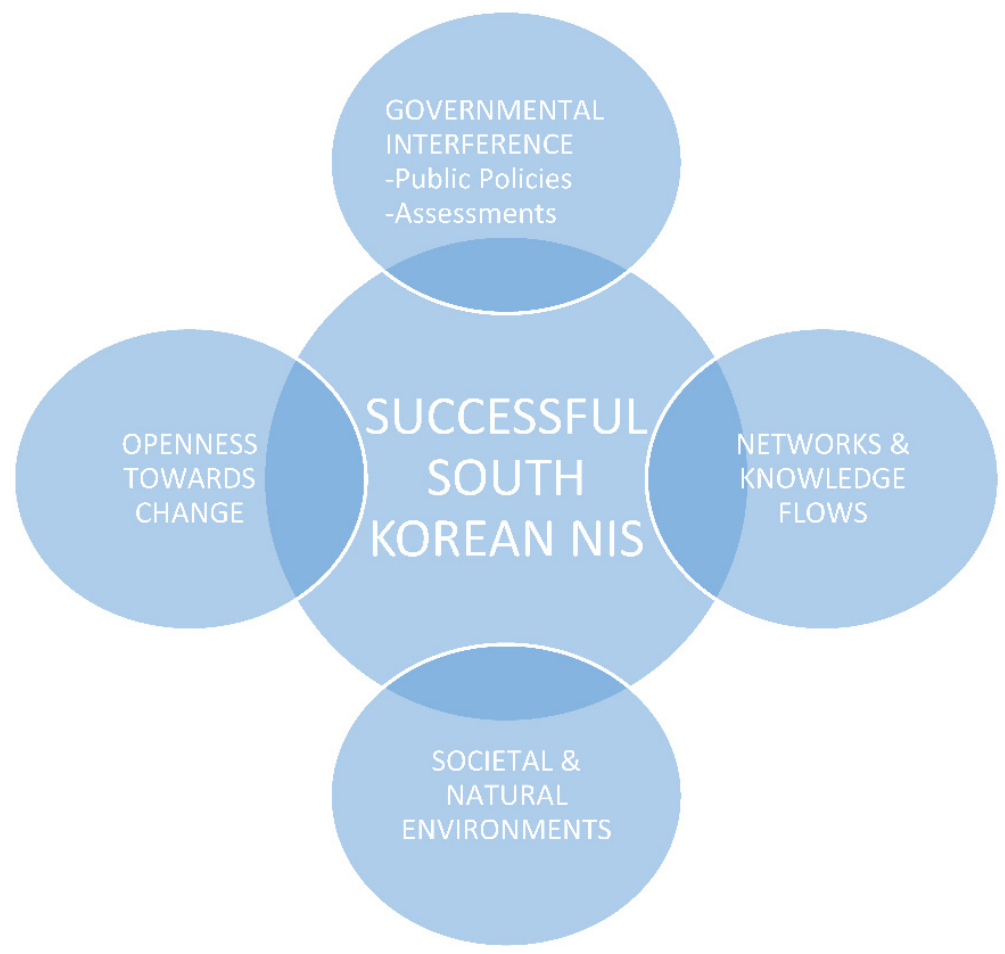

Figure 4. Qualitative innovation factors in South Korea. Source: Own illustration.

\subsection{Quantitative Part}

This research aimed to identify statistically significant relationships and not define how the independent variables influence the dependent variable. Therefore, the multiple, linear, least-squares regression results, which enabled an answer to the research questions in this paper, are not to be interpreted according to their exact $B$-coefficients. Changes in regression models typically lead to a change in the estimate coefficients, so it is not safe to claim that the degree of change an independent variable inflicts on the dependent variable is seen as the ultimate truth. However, identifying significant relationships between innovation and a country's GDP can be achieved through multiple regression and achieved through the applied model.

Aviisati et al. [19] consider graduates from tertiary education one of the factors leading to innovation in a country. However, tertiary education enrollment and the number of patent grants for non-residents were not proven to significantly impact Korea's GDP as benchmarks for innovation in this model. This does not necessarily mean that these selected innovation factors are insignificant for innovation in a country altogether, but rather than a direct connection between these independent variables and the GDP could not be found in this research. Possibly, a multiple regression analysis using a different dependent variable related to innovation would deliver different results.

The influence of $R \& D$ expenditures on the yield of organizations on an institutional level has been analyzed and proven to exist in multiple research papers [18]. In this paper, the connection between the innovation factor R\&D expenditures and Korea's GDP was analyzed on a macroeconomic level and could not be proven to be statistically significant. This 
might be because monetary investments in other areas influencing the GDP, production, for instance, deliver faster returns of investment. Thus, a significant direct relationship between R\&D and the dependent variable could not be identified through the time series data in this case. Another reason could be that other independent variables in the model were more closely connected to the GDP than R\&D expenditures, and, therefore, that factor was not rated to be significant due to the composition of variables in this model. The amount and the composition of the variables used influence the outcome of the regression analysis. In linear, single regression, using R\&D expenditures exclusively as the independent variable and the GDP as the dependent variable, for instance, a statistically significant relationship in countries could be identified, for example, in the research of Akcali and Sismanoglu. Therefore, it cannot be claimed that a connection between R\&D expenditures as an innovation factor and a country's GDP does not exist, even though the model used in this paper does not support the previous research results [38].

However, one of the standard outputs of R\&D investments, the patents, was significantly connected to Korea's GDP in the model used in this paper. This, at least indirectly, confirms the importance of investments in innovation in countries to achieve competitiveness and sustainable development. Dzialla and Blind's research supports this statement, too [16].

Another statistically significant relationship could be found between Korea's researchers and the country's GDP. While a connection between the number of patents and the number of researchers is undeniable, researchers also contribute to non-measurable qualitative innovations such as new, improved policies that ultimately lead to economic success. Therefore, they had to be included in this model. The number of researchers could be a significant quantifiable indicator of innovation that partly represents qualitative innovation.

\section{Limitations and Further Research Gaps}

This paper focuses on qualitative innovation and quantitative innovation benchmarks and how they impact the outperforming emerging market in South Korea. The GDP of a country is influenced by and connected to numerous variables and factors. Innovation and the quantitative components innovation is composed of are only one of these factors. Therefore, this paper's regression model aims to identify possible relationships between independent variables and the dependent variable, analyzing data from the past but limited to reliable predictions regarding the GDP.

The accuracy of a multiple regression vanishes when too many independent variables are being tested at once. Thus, not every factor connected to innovation and which might be positively correlated to the GDP can be included in the model. For this reason, only the most apparent quantitative factors discovered through the literature review have been used for the multiple regression.

It is pertinent to note that the multiple regression model is, just like any model, based on certain assumptions about the data used. These assumptions need to be met for a large part of the model to work. However, working with multiple independent variables over a specific time frame on a macro-economic level, underlying assumptions cannot be met for 100\%, which means that results can be slightly distorted, despite a high $r$ squared and good results in the Durbin-Watson test. When measuring the chosen leading indicators of innovation and their impact on a country's GDP on a macro-economic level through multiple regression, multicollinearity cannot be avoided altogether. The independent variables selected as benchmarks for impactful innovation in this model are necessarily connected to innovation and, therefore, not entirely independent from each other. The latter causes the $\beta$-coefficient estimates to be sensitive to changes in the model. The $p$-values of the regression results, however, are stable despite experimentally inflicted changes of the model. It means that while significant relationships between the tested variables could be identified, the exact $\$$-coefficients are not suitable for making reliable predictions for the GDP development through the selected innovation factors in the used model.

This paper aimed to measure the quantitative components of innovation and those that impact economic success. As an extension of this research, it would make sense to test the 
impact of innovation on the GDP, through the innovation index, for instance, once the index data is available over a sufficient number of years to work with a regression analysis. Such an approach would have higher predictive power than the research conducted in this paper.

Furthermore, innovation is composed of quantitative and qualitative factors. This paper merely focuses on quantifiable innovation benchmarks. Therefore, a detailed analysis of the qualitative factors should be conducted as well in order to fully understand the extent to which the economic success of the outperforming market of South Korea is connected to innovation.

Additionally, it would be beneficial to focus on investigating the direct and indirect links between environmental, social and governance (ESG) practices and the financial performance of key South Korean innovative companies using the mediate role of green innovation [39].

Another interesting point to be researched is the microeconomic aspect of innovationrelated results. "In the present era of globalisation, companies of emerging economies are facing new challenges. Severe competition, rapid technological change, wide volatility in real and financial markets etc., have increased the burden on managers to deliver 'superior' performance, and 'value' for their shareholders" [40]. Thus, the impact of innovation on financial result of key South Korean companies could be analyzed.

"Recent studies on SMEs and their contribution to growth have shown that framework conditions within which they operate and an entrepreneurial culture are key factors in establishing the extent of SME performance and consequently their contribution to macroeconomic growth" [41]. Another important research gap to be covered in the future is the analysis of the contribution of South Korean SMEs to innovation and growth of the economy.

Another relevant aspect of future research is related to the fact that "in the last few years there have been new concepts about innovation and the introduction of a new concept known as the open innovation model. This model is characterised by a variety of actors and new interactions between them. From this perspective, innovation involves research systems, production systems, and governmental/institutional systems. In the innovation process and in the process of transferring technology to businesses, an important role is realised by both formal and informal investors such as banks, venture capitalists, and angel investors" [42]. Therefore, it would be relevant to analyze the role of venture capital in the innovation system. Additionally, "a pivotal role is played by innovative work behaviour (IWB) for the lasting existence of knowledge-intensive business organisations. Although it is significant to be innovative and creative, the influences of this innovation and creativity on the economy and its growth in the future are still inadequate. This conceptual research, supported by the social capital theory (SCT) and self-determination theory (SDT), attempts to focus on vital predictors that are important for promoting tacit knowledge sharing (KS)" [43] could be further researched in the case of South Korea. A special focus should be given to venture capital as "independent, professionally managed, dedicated pools of capital that focus on equity or equity-linked investments in privately held, high growth companies [44]".

\section{Conclusions}

In all three analyzed cases, the case-study analysis revealed that the implementations of public policies, as a subfactor of governmental interference, considerably contributed to the development of South Korea's innovation system. The Korean government prioritized new institutions dedicated to innovation and evaluating their efficiency to maximize the national innovational output. Knowledge flows and networks could be revealed to be a valuable tool for enhancing the efficiency of such institutions through an improved technology transfer and flow of information [31-33].

Thus, knowledge flows and networks notably contributed and continue to contribute to the economic success of South Korea. The collectivistic and hierarchical societal features and values embedded in the Korean high-context culture turned out to be a relevant factor in accepting governmental interference, new policies, and networking enhancing institutions in the development process of Korea's innovation system. 
For these reasons, the cultural and social environment is a relevant influence factor for creating successful innovation systems. In the Republic of Korea, the cultural features were beneficial for the society's openness towards change and new ideas. The openness and readiness of the market were crucial in this research, as it is required to establish creative and entrepreneurial environments within organizations and create networks and clusters comprising public and private research institutions. Furthermore, it is a precondition for the openness of firms and other institutions towards the use of external information or innovation purposes [31-33].

The impact of five quantifiable innovation benchmarks on Korea's GDP was analyzed through a linear, multiple least squares regression to identify statistically significant relationships between the independent variables and the GDP as a benchmark for economic growth. Data from 1995 to 2018 was used. Two out of five selected quantifiable innovation factors exhibit a relationship to Korea's GDP that could be statistically significant. The number of patent grants by residents and the number of researchers per million people shows an incredibly close relationship with the country's economic growth from 1995. Therefore, it can be said that a high number of researchers per million people and high patent grants of residents contribute significantly to economic success in the outperforming emerging market in South Korea.

In the analyzed country, the most crucial quantitative innovation components have been identified through the conducted research. The number of patent grants of residents is a relatively common benchmark for measuring innovation and has been proven to significantly impact a country's GDP over time, once again through the model's results in this paper. Additionally, the discovery of the number of researchers per million people as a statistically significant innovation factor is an essential result of this analysis because the output of researchers is not always quantifiable but also involves qualitative contributions, such as the development of new policies, that lead to economic success as well. Therefore, they represent the interface between quantitative and qualitative innovation components and are a useful innovation benchmark used for orientation when determining how innovative a country is.

Even though not all selected quantitative innovation factors could be significantly linked to economic growth independently in this model, it is out of the question that innovation, in general, significantly contributes to economic growth and is one reason for Korea. The results of the multiple regression in this paper, where two innovation factors showed a significant relationship with the development of Korea's GDP over the years, confirm this statement.

One needs to be aware of each economy's uniqueness when transferring the significant innovation benchmarks identified in this paper to other economies. To estimate the exact composition of quantifiable innovation factors in other economies, our approach can be repeated with other countries' data, and the method used in this paper can function as a template. To deliver a genuinely holistic perspective on the composition of innovation in a country, it is necessary to consider qualitative innovation factors.

From the viewpoint of South Korean firms, the findings of our analysis suggest that whereas pursuing aggressive technology strategies may often be a promising approach, it does not improve a firm's competitive position unconditionally. When the market and technological regimes and a firm's internal capabilities are at odds against such strategies, they are almost certainly doomed to failure. Thus, managers of Korean firms should consider these internal and external factors before deciding to advance into new, unfamiliar technological fields. Finally, managers of firms from other, particularly Western countries should be aware of the commonalities and differences between their and South Korean firms when dealing with them as competitors or partners in strategic alliances. Korean firms are very advanced and effective regarding the implementation of various $R \& D$ management practices. However, considerable differences set them apart in areas like strategic behavior and technology sourcing. Therefore, their innovation management should never be assumed to be fundamentally similar in general. 
Author Contributions: Conceptualization, V.B. and T.M.H.; methodology, V.B. and T.M.H.; validation, T.H. and F.M.; formal analysis, T.M.H.; investigation, V.B. and T.M.H.; data curation, T.M.H.; writing-original draft preparation, T.H. and F.M.; writing-review and editing, V.B. and T.M.H.; visualization, T.M.H.; supervision, V.B.; project administration, T.H. and F.M. All authors have read and agreed to the published version of the manuscript.

Funding: This research received no external funding.

Conflicts of Interest: The authors declare no conflict of interest.

\section{Appendix A}

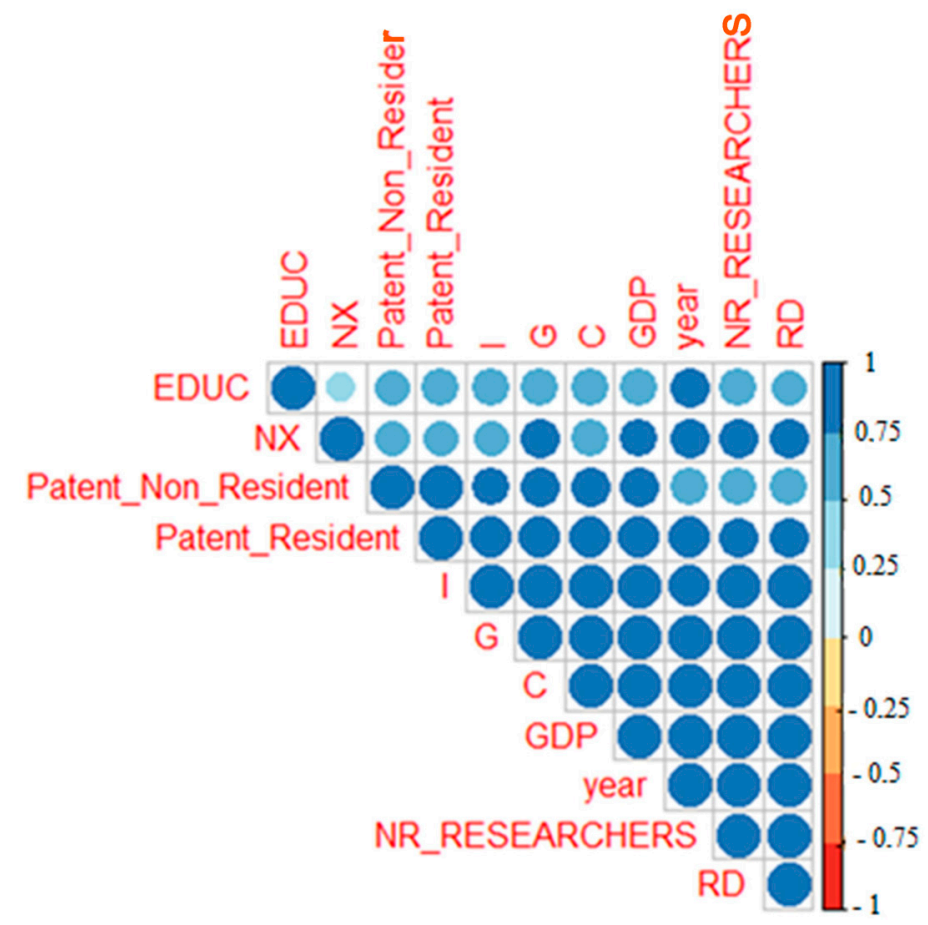

Figure A1. Correlation plot of variables used for exploratory data analysis. Source: Own calculation \& illustration.

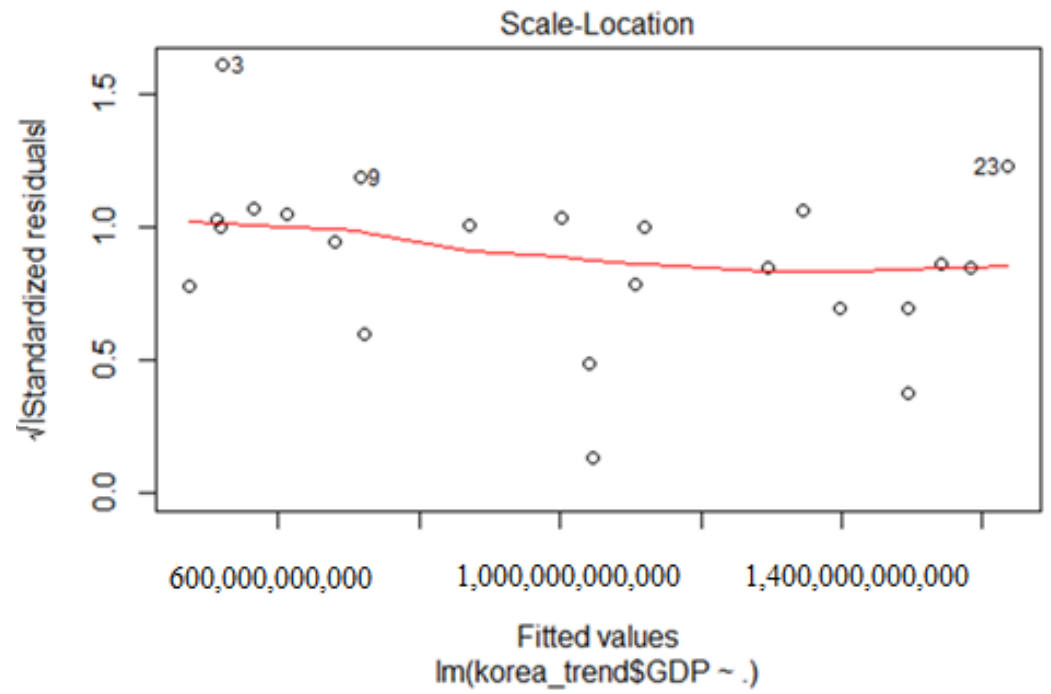

Figure A2. Q-Q Plot residuals. Source: Own calculation \& illustration. 


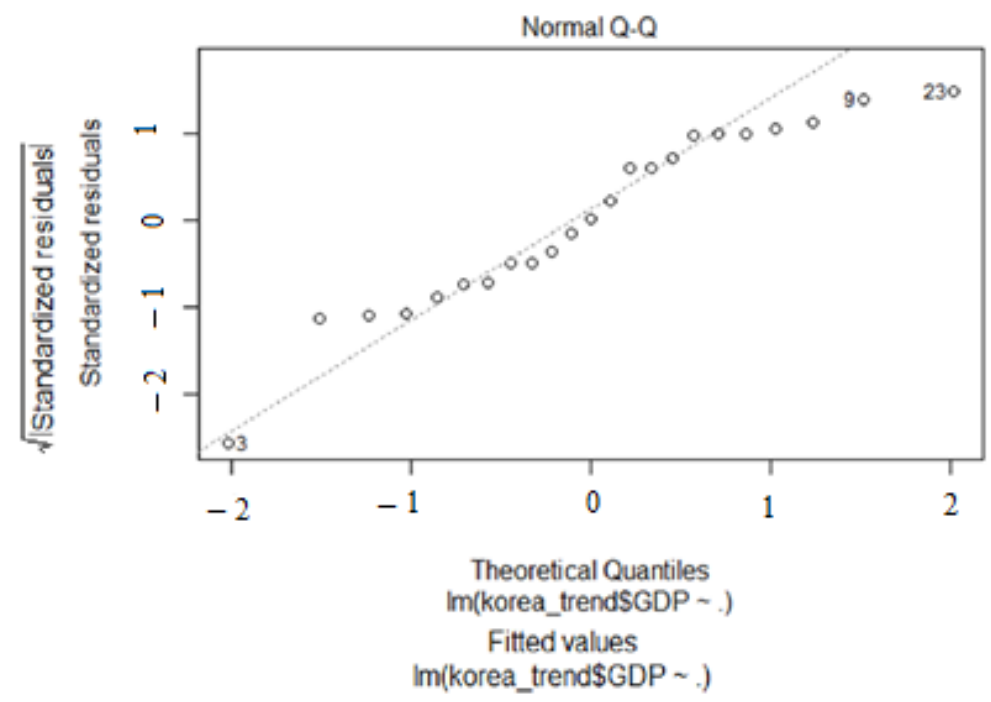

Figure A3. Residuals vs. fitted plot. Source: Own calculation \& illustration.

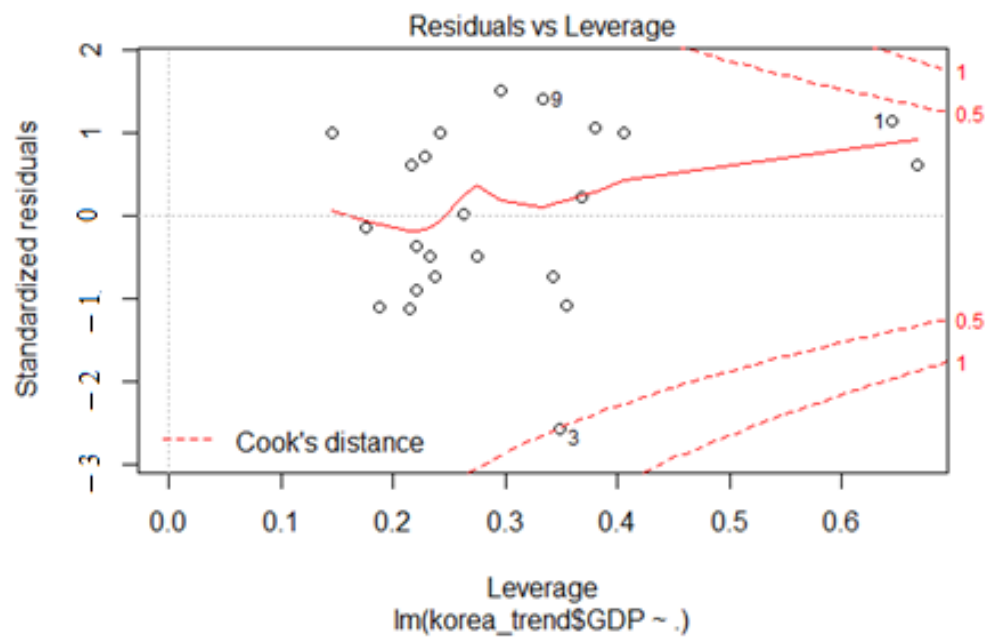

Figure A4. Scale location plot residuals. Source: Own calculation \& illustration.

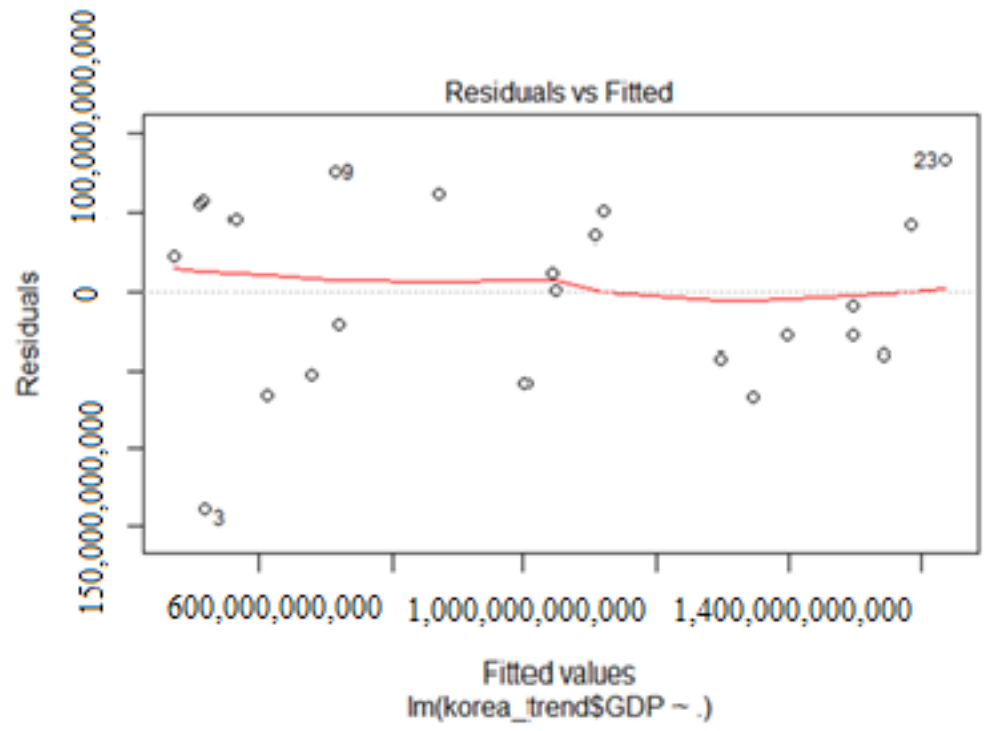

Figure A5. Residuals vs. leverage plot. Source: Own calculation \& illustration. 


\section{References}

1. Sudhir, K.; Priester, J.; Shum, M.; Atkin, D.; Foster, A.; Iyer, G.; Jin, G.; Keniston, D.; Kitayama, S.; Mobarak, M.; et al. Research Opportunities in Emerging Markets: An Inter-disciplinary Perspective from Marketing, Economics, and Psychology. Cust. Needs Solut. 2015, 2, 264-276. [CrossRef]

2. McKinsey Global Institute. Outperformers: High-Growth Emerging Economies and the Companies that Propel Them; McKinsey Global Institute: San Francisco, CA, USA; Brussels, Belgium, 2018.

3. Hasan, S.; Klaiber, A.; Sheldon, I. Regional innovation policy in Taiwan and South Korea: Impact of science parks on firmproductivity distributions. Small Bus. Econ. 2013, 54, 1-40.

4. Baur, N.; Jungmann, R.; Ametowobla, D. Methods of Innovation Research: Qualitative, Quantitative, and Mixed Methods Approaches. 2015. Available online: https://www.researchgate.net/publication/278515232_Methods_of_Innovation_Research_ Qualitative_Quantitative_and_Mixed_Methods_Approaches (accessed on 13 November 2020).

5. World Intellectual Property Organization. World Intellectual Property Indicators; World Intellectual Property Organization: Geneva, Switzerland, 2015.

6. Worldbank. Countries I Data. 2020. Available online: https://data.worldbank.org/country (accessed on 25 October 2020).

7. Ady, P. Growth Models for Developing Countries. In Employment, Income Distribution and Development Strategy: Problems of the Developing Countries: Essays in Honor of H. W. Singer; Cairncross, A., Puri, M., Eds.; Palgrave Macmillan: London, UK, 1976; pp. 106-119. [CrossRef]

8. Dalgaard, C.-J.; Erickson, L. Solow Versus Harrod-Domar: Reexamining the Aid Costs of the First Millennium Development Goal. IMF Work. Pap. 2006, 6, 1. [CrossRef]

9. Mixon, J.W.; Sockwell, W.D. The Solow Growth Model. J. Econ. Educ. 2007, 38, 483. [CrossRef]

10. Ra, K.D.R. Critical Introduction of Solow Growth Theory. J. Humanit. Soc. Sci. 2019, 7, 2321-9467.

11. Barbier, E.B. Endogenous Growth and Natural Resource Scarcity. Environ. Resour. Econ. 1999, 14, 51-74. [CrossRef]

12. Fedderke, J. Technology, Human Capital, Growth, and Institutional Development: Lessons from Endogenous Growth Theory; Working Paper No. 27; University of Cape Town: Capetown, South Africa, 2005.

13. Barro, R.J.; Sala-i-Martin, X.; England, L. Macroeconomics, 2nd ed.; MIT Press: Cambridge, MA, USA, 1987.

14. Schilirò, D. The Growth Conundrum: Paul Romer's Endogenous Growth. Int. Bus. Res. 2019, 12, 75. [CrossRef]

15. OECD. OSLO Manual 2018: Guidelines for Collecting, Reporting, and Using Data on Innovation; OECD: Paris, France, 2018.

16. Dziallas, M.; Blind, K. Innovation indicators throughout the innovation process: An extensive literature analysis. Technovation 2019, 80-81, 3-29. [CrossRef]

17. Yang, C.-H. Is innovation the story of Taiwan's economic growth? J. Asian Econ. 2006, 17, 867-878. [CrossRef]

18. Raymond, L.; St-Pierre, J. R\&D as a determinant of innovation in manufacturing SMEs: An attempt at empirical clarification. Technovation 2010, 30, 48-56. [CrossRef]

19. Avvisati, F.; Jacotin, G.; Vincent-Lancrin, S. Educating Higher Education Students for Innovative Economies: What International Data Tell Us. Tuning J. High. Educ. 2013, 1, 223-240. [CrossRef]

20. World Bank. Tertiary Education [Text/HTML]. 2020. Available online: https://www.worldbank.org/en/topic/tertiaryeducation (accessed on 19 January 2021).

21. OECD. OECD Glossary of Statistical Terms-Knowledge-Based Economy Definition. 2020. Available online: https://stats.oecd. org/glossary/detail.asp?ID=6864 (accessed on 17 October 2020).

22. Runfola, A.; Perna, A.; Baraldi, E.; Gregori, G.L. The use of qualitative case studies in top business and management journals: A quantitative analysis of recent patterns. Eur. Manag. J. 2017, 35, 116-127. [CrossRef]

23. Krusenvik, L. Using Case Studies as a Scientific Method: Advantages and Disadvantages; Halmstad University, School of Business, Engineering and Science: Halmstad, Sweden, 2016.

24. Göthlich, S. Fallstudien als Forschungsmethode: Plädoyer für Einen Methodenpluralismus in der Deutschen Betriebswirtschaftlichen Forschung. Institute of Business Administration. 2003. Available online: https://www.econstor.eu/handle/10 419/147639 (accessed on 15 December 2020).

25. Statistics Solutions. Multiple Regression. 2020. Available online: https://www.statisticssolutions.com/regression-analysismultiple-regression/ (accessed on 9 December 2020).

26. Davenport, T.H.; Kim, J. A Refresher on Regression Analysis. Harvard Business Review. 4 November 2015. Available online: https:/ / hbr.org/2015/11/a-refresher-on-regression-analysis (accessed on 22 December 2020).

27. Yale Stats. Multiple Linear Regression. 2020. Available online: http://www.stat.yale.edu/Courses/1997-98/101/linmult.htm (accessed on 7 January 2021).

28. Lindstrom, D. Schaum's Easy Outline of Statistics: The Fast Way to Top Grades, 2nd ed.; McGraw Hill Education: New York, NY, USA, 2010.

29. Grace-Martin, K. Interpreting the Intercept in a Regression Model. The Analysis Factor. 12 February 2009. Available online: https:/ / www.theanalysisfactor.com/interpreting-the-intercept-in-a-regression-model/ (accessed on 9 January 2021).

30. Hayes, A. Error Term. Investopedia. 2020. Available online: https://www.investopedia.com/terms/e/errorterm.asp (accessed on 14 February 2021). 
31. Lee, P.C.; Su, H.N. Evolution of science, technology and innovation policy in Asia: Case of China, South Korea, Japan, and Taiwan. In Proceedings of the 2015 Portland International Conference on Management of Engineering and Technology (PICMET), Portland, OR, USA, 2-6 August 2015; pp. 184-191. [CrossRef]

32. Gang, K.; Abetti, P.A. The global competitiveness of South Korea: The role of government-funded research institutes. World Rev. Sci. Technol. Sustain. Dev. 2010, 8, 1. [CrossRef]

33. Lee, S.; Park, G.; Yoon, B.; Park, J. Open Innovation in SMEs-An Intermediated Network Model. Res. Policy 2010, 39, 290-300. [CrossRef]

34. Corporate Finance Institute. R-Squared-Definition, Interpretation, and How to Calculate. 2020. Available online: https: / / corporatefinanceinstitute.com/resources/knowledge/other/r-squared/ (accessed on 26 January 2021).

35. McPherson, G. Statistics in Scientific Investigation: Its Basis, Application, and Interpretation; Springer Science \& Business Media: Berlin/Heidelberg, Germany, 2013.

36. Hoaglin, D.C.; Mosteller, F.; Tukey, J.W. Exploring Data Tables, Trends, and Shapes; John Wiley \& Sons: Hoboken, NJ, USA, 2011.

37. Durbin, J.; Watson, G.S. Testing for Serial Correlation in the least Squares Regression. Biometrika 1950, 37, 409-428. [CrossRef] [PubMed]

38. Akcali, B.Y.; Sismanoglu, E. Innovation and the Effect of Research and Development (R\&D) Expenditure on Growth in Some Developing and Developed Countries. Procedia-Soc. Behav. Sci. 2015, 195, 768-775. [CrossRef]

39. Chouaibi, S.; Chouaibi, J.; Rossi, M. ESG and corporate financial performance: The mediating role of green innovation: UK common law versus Germany civil law. EuroMed J. Bus. 2021, 9, 1450-2194. [CrossRef]

40. Lal, B.M.; Shaikh, J.M. Economic value added and shareholders' wealth creation: The portrait of a developing Asian country. Int. J. Manag. Financ. Account. 2013, 5, 2013. [CrossRef]

41. Rossi, M.; Lombardi, R.; Siggia, D.; Oliva, N. The impact of corporate characteristics on the financial decisions of companies: Evidence on funding decisions by Italian SMEs. J. Innov. Entrep. 2015, 5, 1-14. [CrossRef]

42. Rossi, M. The role of venture capital funds in financing innovation in Italy. Constraints and challenges for innovative small firms. Int. J. Glob. Small Bus. 2015, 7, 162-180. [CrossRef]

43. Vikas, G.; Thomas, A. Fostering tacit knowledge sharing and innovative work behaviour: An integrated theoretical view. Int. J. Manag. Financ. Account. 2019, 11. [CrossRef]

44. Rossi, M.; Thrassou Aand Vrontis, D. Financing innovation: Venture capital investments in biotechnology firms. Int. J. Technol. Mark. 2011, 6, 355-377. [CrossRef] 